\title{
Comparative antibacterial activity of hexachlorophane in different formulations used for skin disinfection
}

\author{
J. W. GIBSON \\ From the Microbiology Laboratory, Izal Limited, Thorncliffe, Sheffield
}

SYNOPSIS Two formulations of hexachlorophane have been compared for their antibacterial effectis in respect of skin disinfection. It was found that the activity of hexachlorophane is dependent upon its vehicle of formulation. A $2 \cdot 5 \%$ soap gel possesses broad-spectrum bactericidal activity with remarkable speed of kill, whereas a $3 \%$ detergent formulation has no bactericidal action against Gram-negative bacteria and only a very slow action against Gram-positive bacteria.

In practice the rapid action of the $2.5 \%$ soap gel against both Gram-negative and Gram-positi transient skin bacteria can be achieved by correctly applying the preparation directly to the dry hands.

It appears that the $2.5 \%$ soap gel does not need to rely on mechanical removal of transient organisms as does the $3 \%$ detergent.

The $2.5 \%$ soap gel is more dependable in its action on the resident bacteria than the $3 \%$ detergent It controlled the resident flora in the skin of all subjects tested whereas the latter appeared to be potentiated on the skin of certain individuals only.

It has been possible to distinguish between the antibacterial effect on the resident organisms and the mere removal of transient bacteria by mechanical action of the $3 \%$ detergent as opposed 9 antibacterial effect on residents and rapid antibacterial effect on transients by the $2.5 \%$ soap get

Many publications in Britain and the United States have described the value of hexachlorophane preparations as skin degerming agents. Various methods have been employed to determine the reduction of organisms, but not all distinguished between antibacterial action and mechanical removal due to the detergency of the preparation. Further, little work has been published on the reasons for using particular vehicles to carry the hexachlorophane. Hufnagel, Walter, and Howard (1948) proposed the use of alkylphenoxypolyether sulphonate as a vehicle for $3 \%$ hexachlorophane. This was claimed to be more effective than the bar soap preparations of Traub, Newhall, and Fuller (1944) and confirmed by Udinski in 1945 and Seastone in 1947. Although Price (1951) had made such statements as the presently popular brief period of hand washing was not as efficacious as had been previously claimed', 'hexachlorophane does not disinfect the skin quickly,

Received for publication 1 May 1968. as alcohol does, but much more slowly . ..., 'this slow degerming is attributed to a film of the age left on the hands after washing with hexachlore phane', 'it is necessary to use hexachlorophane preparations exclusively and frequently', Smylie, Webster, and Bruce in 1959 confirmed the findin of Hufnagel et al.

PROPERTIES OF HEXACHLOROPHANE PRODUCTS

The properties of the various hexachlorophar products should therefore be considered.

SOLID BAR SOAP A known amount of the produet cannot be applied and due to its hardness only? very small fraction of the antiseptic is transferred to the skin. This is further complicated by a subject? individual method of washing. A bar soap can also be contaminated when passed from hand to han especially if the antiseptic is specific against Grant positive organisms. 
LIQUID PREPARATIONS BASED ON DETERGENTS OR SOAP These have the advantage that the skin surface may be subjected to the maximum amount of hexachlorophane before the preparation is diluted with water. It should also be noted that the $3 \%$ hexachlorophane/detergent of Hufnagel et al contained the water-repellent substances lanolin, cholesterol, and white soft paraffin; thus the hexachlorophane may not be reduced in activity by subsequent dilution with water.

Lowbury, Lilly, and Bull (1963) found the $3 \%$ hexachlorophane detergent product superior to a $2 \%$ hexachlorophane bar soap but also found a $2 \%$ hexachlorophane liquid soap equal to the $3 \%$ hexachlorophane detergent. Since the method of test involved washing under running water, the $2 \%$ hexachlorophane liquid soap, not containing waterrepellent substances, could well have been diluted more quickly than the 3\% hexachlorophane detergent, yet worked as well. Lowbury et al concluded that the vehicle for the hexachlorophane seemed to have some effect.

Chemically there is a significant difference between a colloidal suspension of hexachlorophane and a solubilized hexachlorophane in liquid soap, the latter being a molecular dispersion in the soap micelle. The work of Bean and Berry (1953) indicated that the bactericidal activity of a phenol (and hexachlorophane is a phenol) solubilized by a soap is a function of the concentration of phenol in the soap micelle and is independent of the total phenol in the system, provided that micellular saturation is satisfied. It follows that increasing the concentration of a phenol may not improve the bactericidal activity of a formulation and in fact it is the experience of the author that random increase may indeed reduce bactericidal activity.

Hexachlorophane has been stated to be predominantly effective against Gram-positive organisms yet it is frequently used in situations where Gram-negative organisms are of importance. The present paper shows that the vehicle for the hexachlorophane plays a major part in determining its antibacterial activity (even against Gram-negative organisms) and that it is unjust to define the activity of a group of hexachlorophane products on the basis of having tested one number assumed to be representative of the group.

\section{PART I}

In considering relationships between detergent and soap vehicles we carried out simple culture mortality counts comparing a detergent-hexachlorophane formulation with soap gel formulations containing hexachlorophane.
BROAD SPECTRUM EVALUATION Of the formulations, $2 \mathbf{g}$ was inoculated with $0.2 \mathrm{ml}$ of a 24-hour broth culture of Pseudomonas aeruginosa NCTC 7244, Escherichia coli NCTC 9002, Salmonella typhi NCTC 8393, and Staphylococcus aureus NCTC 9789 (phage 80/81).

The formulation and culture were mixed and subcultures taken at intervals of $0.5,2,4,8$, and 16 minutes and serially diluted to give 1 part of hexachlorophane to 333,000 in quarter strength Ringer's solution containing $1 \%$ Tween 80 . The decimal dilutions were plated onto nutrient Tween 80 agar. A loopful of the formulation-culture mixture was also taken straight on to Tween 80 agar and no differences in the results were found from those of the serial dilution method. (Complete inhibition was found with agar containing no Tween 80.)

RESULTS A 3\% hexachlorophane detergent formulation required a period of between eight and 16 minutes to destroy the staphylococcus whilst no reduction in the numbers of the Gram-negative organisms was discerned even over $\mathbf{3 0}$ minutes' contact. A $2.5 \%$ hexachlorophane to $23 \%$ potassium soap gel completely killed all cultures in under two minutes, only 30 seconds being necessary against the staphylococcus and pseudomonas. A $3 \%$ hexachlorophane- $23 \%$ potassium soap gel, although highly active against the staphylococcus, was not as effective against the Gram-negative organisms as was the $2.5 \%$ hexachlorophane soap gel.

The possibility of the $2.5 \%$ hexachlorophane soap gel deriving activity from something other than hexachlorophane was excluded by testing the formulation from which the hexachlorophane had been omitted. This was found devoid of activity against staphylococcus, but some slight activity was found against pseudomonas and salmonella. On comparing minimal inhibition concentrations of the two formulae a very much higher level of activity was found when hexachlorophane was present. The activity of the hexachlorophane soap gel could be neutralized with Tween 80 whereas that of the soap gel without hexachlorophane could not. We were satisfied that the antiseptic effect of a $2.5 \%$ hexachlorophane- $23 \%$ potassium soap gel was essentially a function of the hexachlorophane complex.

Since the results obtained for this gel were surprising on the basis of available literature we decided to extend the preliminary investigation over a wider range of organisms. There seemed little point in evaluating the $3 \%$ hexachlorophane detergent or $3 \%$ hexachlorophane soap gel further since they were so obviously inferior in bactericidal activity.

The method employed was as described above with direct plating of the formulation-culture mixture on to nutrient or blood agar containing Tween 80 . The 
organisms tested and the results obtained are shown in Table I.

\section{TABLE I}

\begin{tabular}{ll} 
Organism & $\begin{array}{c}\text { Maximum } \\
\text { for 100\% }\end{array}$ \\
& Bacterial Kill \\
\hline Staphylococcus aureus (7 strains) & $0 \cdot 5$ \\
Corynebacterium diphtheriae & $0 \cdot 5$ \\
Escherichia coli (6 strains) & 2 \\
Aerobacter aerogenes & 2 \\
Klebsiella pneumoniae & 4 \\
Pseudomonas aeruginosa (5 strains) & $0 \cdot 5$ \\
Pseudomonas fluorescens & $0 \cdot 5$ \\
Proteus morgani, mirabilis, vulgaris & $0 \cdot 5$ \\
Salmonella typhi (5 strains) & 2 \\
Salmonella dublin, enteritidis, typhimurium, & \\
$\quad$ pullorum, cholerae suis & 2 \\
Salmonella paratyphi A and paratyphi C & 2 \\
Shigella dysenteriae, flexneri sonnei & 2 \\
Streptococcus agalactiae, faecalis, hominis, & \\
$\quad$ lactis, 'Viridans', pyogenes (3 strains) & 0.5 \\
Diplococcus pneumoniae & $0 \cdot 5$
\end{tabular}

The encouraging results obtained against both Gram-positive and Gram-negative organisms with this gel prompted us to investigate its effect upon organisms on the skin. The $3 \%$ hexachlorophane detergent formulation was also used for comparison.

\section{PART II}

Throughout the remainder of this paper the $3 \%$ hexachlorophane detergent formulation will be referred to as the $3 \%$ detergent and the $2.5 \%$ hexachlorophane- $23 \%$ potassium soap gel as the $2.5 \%$ soap gel.

REDUCTION OF TRANSIENT ORGANISMS Lowbury, Lilly, and Bull (1964) stated that Staphylococcus aureus is the only common resident pathogen. This organism and others such as Pseudomonas aeruginosa, Escherichia coli, and Salmonella typhi, which become deposited on the skin, may be regarded as representatives of pathogenic transient organisms.

We decided to test the effect of the $2.5 \%$ soap gel and $3 \%$ detergent as rapid antiseptics on transient organisms, excluding their action against the resident flora, and selected Staphylococcus aureus NCTC 9789, Escherichia coli NCTC 9002, Salmonella typhi NCTC 8393, and Pseudomonas aeruginosa NCTC 7244 as test bacteria. Experiments showed the Escherichia to be extremely susceptible to drying; frequently it was impossible to recover viable organisms even from untreated skin, and we discontinued its use. Salmonella and pseudomonas also showed some tendency to die naturally when in contact with a dry skin. This effect was overcome by moistening the skin with sterile distilled water and allowing it to dry in air before inoculating with
Salmonella typhi, or by allowing a very short time drying between inoculation with Pseudomonas aeruginosa and application of the antiseptic.

$\stackrel{5}{+}$

METHOD Before each test the hands were swabbed wion $70 \%$ alcohol and allowed to dry. A $1 \mathrm{~mm}$ loopful of the appropriate culture was spread over the finger tips of each hand and when dry the formulations were spread over the inoculated areas of the left hand and allowed co act for 30 seconds before swabbing with calcium alginate swabs. The swabs were immediately immersed in $10 \mathrm{ml}$-ef Calgon Ringer Tween 80 solution. ${ }^{1}$ The right hand werass similarly inoculated, but without any antiseptic beigg applied and served as a control. It was calculated thet $0.025 \mathrm{~g}$ was picked up by a swab which diluted to $1 / 400 \mathrm{on}$ immersion in the $10 \mathrm{ml}$ of Calgon Ringer-Tween 80 solution. This was serially diluted 10,100 , and 1,000 -ford and pour plates were prepared from $1 \mathrm{ml}$ of each dilution in $15 \mathrm{ml}$ of nutrient agar containing $1 \%$ Tween 80 . From earlier investigation we were satisfied that any bacteriostatic effect of carried over antiseptic would be completely neutralized at the first stage, that is, on placing the swab in the $10 \mathrm{ml}$ of Calgon Ringer-Tween solution. By adopting the above method, applying the formulations without a washing action we were able to distinguiş between true antiseptic effect and mechanical reductiog of organisms.

RESULTS Tables II and III show the results of these experiments. As may be seen, the $2.5 \%$ soap 1 largely reduced the numbers of all three test orga isms. It may also be seen that the effect of the $3 \frac{\%}{40}$ detergent formulation was comparatively insignficant except for a small reduction against Staph lococcus aureus only.

\section{PART III}

SUPPRESSION OF RESIDENT ORGANISMS A use $f \stackrel{\bar{g}}{\bar{g}}$ ir hexachlorophane preparations is the maintenance of near sterility inside the gloves of surgeons. Even though transient organisms may be controlled by scrubbing up before donning gloves deep-seated resident staphylococci are constantly reaching the skin surface by perspiration and movement. On the hypothesis that hexachlorophane deposits as a film on the skin and perhaps in the pores, any staphis lococci reaching the skin surface will come inte contact with it and be destroyed before escapixg through a damaged glove. It was decided to test efficiency of the $2.5 \%$ soap gel and the $3 \%$ deterge over a contact time of one hour in surgical gloves.

METHOD A timetable was devised employing the two

'Calgon Ringer-Tween 80 solution was prepared from Calgon Ring solution tablets (Oxoid code no. BR.49) which provide a solution containing $1 \%$ Calgon in quarter strength Ringer solution (Higgi通, 1950). One per cent of Tween 80 was added to this. 
TABLE II

RANGE OF VIABLE COUNTS AFTER 30-SECOND CONTACT WITH $2 \cdot 5 \%$ HEXACHLOROPHANE-23\% POTASSIUM SOAP GEL

Five Tests for Each Subject

\begin{tabular}{|c|c|c|c|c|c|}
\hline & & & & & \\
\hline & J.W.L. & J.M.C. & J.A. & $J . S$. & $\boldsymbol{K} . \boldsymbol{W}$. \\
\hline \multicolumn{6}{|c|}{ Staphylococcus aureus NCTC 9789 and $2.5 \%$ Hexachlorophane- $23 \%$ Potassium Soap } \\
\hline Neat & $0-2$ & $0-3$ & $0-3$ & $0-8$ & $0-3$ \\
\hline \multicolumn{6}{|c|}{ There were no viable counts for dilutions $1 / 10,1 / 100,1 / 1,000$} \\
\hline \multicolumn{6}{|c|}{ Control $^{1}$} \\
\hline Neat & $5+->5+$ & $3+->5+$ & $2+->5+$ & $>5+$ & $3+->5+$ \\
\hline $1 / 10$ & $60-2+$ & $39->5+$ & $17->5+$ & $98->5+$ & $\begin{array}{l}34-5+ \\
1-45\end{array}$ \\
\hline $\begin{array}{l}1 / 100 \\
1 / 1,000\end{array}$ & $\begin{array}{l}4-30 \\
1-8\end{array}$ & $\begin{array}{l}4-3+ \\
0-12\end{array}$ & $\begin{array}{l}5-4+ \\
0-40\end{array}$ & $\begin{array}{l}10-5+ \\
2-9\end{array}$ & $\begin{array}{l}1-45 \\
0-3\end{array}$ \\
\hline \multicolumn{6}{|c|}{ Pseudomonas aeruginosa NCTC 7244 and $2.5 \%$ Hexachlorophane- $23 \%$ Potassium Soap } \\
\hline Neat & $0-1$ & 0 & $0-6$ & $0-2$ & 0 \\
\hline \multicolumn{6}{|c|}{ There were no viable counts for dilutions $1 / 10,1 / 100,1 / 1,000$} \\
\hline \multicolumn{6}{|c|}{ Control } \\
\hline $\begin{array}{l}\text { Neat } \\
1 / 10\end{array}$ & $\begin{array}{l}>5+ \\
2+->5+\end{array}$ & $\begin{array}{l}200->5+ \\
6->5+\end{array}$ & $\begin{array}{l}4+->5+ \\
35->5+\end{array}$ & $\begin{array}{l}4+->5+ \\
30->5+\end{array}$ & $\begin{array}{l}3+->5+ \\
43->5+\end{array}$ \\
\hline $\begin{array}{l}1 / 10 \\
1 / 100\end{array}$ & $\begin{array}{l}2+->5+ \\
20->5+\end{array}$ & $\begin{array}{l}6->5+ \\
0->5+\end{array}$ & $\begin{array}{l}35-3+ \\
2-3+\end{array}$ & $\begin{array}{l}30-5+ \\
1-5+\end{array}$ & $\begin{array}{l}43->3+ \\
0-3+\end{array}$ \\
\hline $1 / 1,000$ & $0-228$ & $0-5+$ & $0-40$ & $2-50$ & $0-24$ \\
\hline \multicolumn{6}{|c|}{ Salmonella typhi NCTC 8393 and $2.5 \%$ Hexachlorophane- $23 \%$ Potassium Soap } \\
\hline Neat & 0 & $\mathbf{0}$ & $0-4$ & $0-2$ & $\mathbf{0}$ \\
\hline \multirow{2}{*}{\multicolumn{6}{|c|}{ Control }} \\
\hline & & & & & \\
\hline Neat & $79-4+$ & $31-3+$ & $104-5+$ & $22->5+$ & $33-93$ \\
\hline $1 / 10$ & 4-32 & $2-27$ & $10->5+$ & $6-4+$ & $3-7$ \\
\hline $1 / 100$ & $0-4$ & $0-6$ & $0-3+$ & $0-2+$ & 0 \\
\hline $1 / 1,000$ & 0 & 0 & $0-20$ & $0-27$ & 0 \\
\hline
\end{tabular}

$>5+=$ considerably greater than $500 ; 5+=500$ approximately $; 4+=400-499 ; 3+=300-399 ; 2+=200-299$.

'Neat' = swab immersed in $10 \mathrm{ml}$ Calgon/Ringer/Tween $80,1 \mathrm{ml}$ for pour plates.

'Neat' serially diluted to $1 / 10,1 / 100,1 / 1,000$ (see text for actual dilution of formulations), $1 \mathrm{ml}$ of each for pour plates.

${ }^{1}$ Control was inoculated with culture only.

hexachlorophane preparations and an unmedicated bar soap. The timetable is set out below.

Formulation

No. of Days of Test

\section{Bar soap}

$2 \cdot 5 \%$ Soap gel

Bar soap

$3 \%$ Detergent

Bar soap

Experiments were as continuous as possible, but no work was done on Saturdays or Sundays.

1 Unmedicated bar soap The hands were washed for two-and-a-half minutes with the soap, then rinsed for a further minute. Sterile distilled water at approximately $40^{\circ} \mathrm{C}$ was used for both washing and rinsing. We have preferred this, since earlier examination of some hospital and laboratory water supplies had shown us that they might be grossly contaminated with organisms which could confuse viable counts, or be mistaken for staphylococci.

$22.5 \%$ Soap gel The preparation was added to the dry hands from a specially made dispenser $(1 \mathrm{~g}$ gel to two hands), rubbed into the skin for 30 seconds, and then rinsed off in the sterile distilled water at $40^{\circ} \mathrm{C}$.

$33 \%$ Detergent The hands were wetted with sterile distilled water and the $3 \%$ detergent preparation added (approximately $1 \mathrm{~g}$ ) from an appropriate dispenser (as recommended and supplied by the manufacturer). The hands were washed by gradually adding more sterile distilled water until all of the preparation appeared to be washed off, a procedure which took about two-and-a-half minutes.

After rinsing in sterile distilled water, the hands were dried with a sterile towel.

Sterile rubber gloves were worn for one hour.

After one hour the gloves were removed, excess glove powder was shaken from the fingers and the finger tips were streaked over nutrient agar containing $1 \%$ Tween 80 (one plate/hand).

The plates were incubated at $37^{\circ} \mathrm{C}$ for 24 hours and the colonies counted. After re-incubation for a further 24 hours the colonies were counted again.

Plates showing sterility or near sterility were streaked with 1 in 100,000 dilutions of 24-hour broth cultures of Staphylococcus aureus and Escherichia coli. No inhibitory effects were noted.

RESULTS The results are shown in Table IV. Colonies were not typed biochemically, but after 24 hours' incubation there appeared to be a predominance of staphylococci except in the case of R.G. whose colonies were more varied. After 48 hours' incubation the numbers of staphylococci had not appeared to increase, but increases were recorded in the numbers of non-staphylococcal colonies. 
TABLE III

RANGE OF VIABLE COUNTS AFTER 30-SECOND CONTACT WITH $3 \%$ HEXACHLOROPHANE DETERGENT FORMULATION

\begin{tabular}{|c|c|c|c|c|c|}
\hline & \multicolumn{5}{|c|}{ Five Tests for Each Subject } \\
\hline & J.W.L. & J.M.C. & J.A. & $J . S$. & $\boldsymbol{K} . \boldsymbol{W}$. \\
\hline $\begin{array}{c}\text { Staphyloco } \\
\text { Neat } \\
1 / 10 \\
1 / 100 \\
1 / 1,000\end{array}$ & $\begin{array}{l}\text { orophane De } \\
10-4+ \\
0-34 \\
0-40 \\
0-1\end{array}$ & $\begin{array}{l}t \\
96-3+ \\
4-30 \\
0-1 \\
0\end{array}$ & $\begin{array}{l}99->5+ \\
22-4+ \\
0-17 \\
0-1\end{array}$ & $\begin{array}{l}66->5+ \\
2-2+ \\
0-5 \\
0-3\end{array}$ & $\begin{array}{l}8-2+ \\
0-25 \\
0-5 \\
0\end{array}$ \\
\hline $\begin{array}{c}\text { Control }{ }^{1} \\
\text { Neat } \\
1 / 10 \\
1 / 100 \\
1 / 1,000\end{array}$ & $\begin{array}{l}104->5+ \\
10->5+ \\
0->3+ \\
0-6\end{array}$ & $\begin{array}{l}5+->5+ \\
64-3+ \\
4-58 \\
1-11\end{array}$ & $\begin{array}{l}>5+ \\
138-5+ \\
10-66 \\
0-16\end{array}$ & $\begin{array}{l}2+->5+ \\
34-2+ \\
0-36 \\
0-7\end{array}$ & $\begin{array}{l}2+->5+ \\
32-2+ \\
3-37 \\
0-5\end{array}$ \\
\hline $\begin{array}{c}\text { Pseudomon } \\
\text { Neat } \\
1 / 10 \\
1 / 100 \\
1 / 1,000\end{array}$ & $\begin{array}{l}\text { hlorophane } \\
88->5+ \\
9-3+ \\
1-33 \\
0-1\end{array}$ & $\begin{array}{l}68->5+ \\
5-5+ \\
2-4+ \\
0-54\end{array}$ & $\begin{array}{l}>5+ \\
136-5+ \\
15-77 \\
1-10\end{array}$ & $\begin{array}{l}3+->5+ \\
34->5+ \\
2-32 \\
0-5\end{array}$ & $\begin{array}{l}2+->5+ \\
24-2+ \\
0-42 \\
0-3\end{array}$ \\
\hline $\begin{array}{c}\text { Control } \\
\text { Neat } \\
1 / 10 \\
1 / 100 \\
1 / 1,000\end{array}$ & $\begin{array}{l}55->5+ \\
7-5+ \\
0-115 \\
0-28\end{array}$ & $\begin{array}{l}5+->5+ \\
64>5+ \\
6-2+ \\
0-26\end{array}$ & $\begin{array}{l}>5+ \\
4+->5+ \\
48-3+ \\
10-46\end{array}$ & $\begin{array}{l}>5+ \\
172->5+ \\
20-5+ \\
1-44\end{array}$ & $\begin{array}{l}2+->5+ \\
18-3+ \\
1-53 \\
0-4\end{array}$ \\
\hline $\begin{array}{c}\text { Salmonella } \\
\text { Neat } \\
1 / 10 \\
1 / 100 \\
1 / 1,000\end{array}$ & $\begin{array}{l}\text { ane Detergen } \\
76->5+ \\
0-2+ \\
0-12 \\
0-4\end{array}$ & $\begin{array}{l}76-3+ \\
6-36 \\
0-10 \\
0\end{array}$ & $\begin{array}{l}45->5+ \\
4-113 \\
0-13 \\
0-3\end{array}$ & $\begin{array}{l}48->5+ \\
3-3+ \\
0-26 \\
0-12\end{array}$ & $\begin{array}{l}13->5+ \\
2-88 \\
0-22 \\
0-10\end{array}$ \\
\hline $\begin{array}{c}\text { Control } \\
\text { Neat } \\
1 / 10 \\
1 / 100 \\
1 / 1,000\end{array}$ & $\begin{array}{l}111->5+ \\
7-5+ \\
1-80 \\
0-12\end{array}$ & $\begin{array}{l}38->5+ \\
10->5+ \\
0-72 \\
0-2\end{array}$ & $\begin{array}{l}66->5+ \\
5->5+ \\
2-2+ \\
0-34\end{array}$ & $\begin{array}{l}43->5+ \\
1-3+ \\
0-40 \\
0\end{array}$ & $\begin{array}{l}29->5+ \\
1-74 \\
0-25 \\
0-4\end{array}$ \\
\hline
\end{tabular}

$>5+=$ considerably greater than $500 ; 5+=500$ approximately $; 4+=400-499 ; 3+=300-399 ; 2+=200-299$.

'Neat' = swab immersed in $10 \mathrm{ml}$ Calgon/Ringer/Tween $80,1 \mathrm{ml}$ for pour plates. 'Neat' serially diluted to $1 / 10,1 / 100,1 / 1,000$ (see text f actual dilution of formulations), $1 \mathrm{ml}$ of each for pour plates.

${ }^{1}$ Control was inoculated with culture only.

The results show very low counts from all subjects using the $2.5 \%$ soap gel with the possible exception of R.G. It was discovered that R.G. had been using a water-resistant barrier cream at this time which might have prevented the hexachlorophane preparation from penetrating the pores. The results for the $3 \%$ detergent show moderately low counts on J.A., J.S., and R.G. but J.W.L. and J.M.C. were different in showing (1) a higher total number of survivors, and (2) an increase in survivors between 24 and 48 hours' incubation.

It is interesting to note that both preparations gave low viable counts compared with bar soap at the first and subsequent washings, which is against the accepted thinking that most hexachlorophane preparations have a delayed effect due to cumulative action of the antiseptic on repeated application. The reason for this rapid action is not clear, but may be due to the wearing of gloves when skin secretions solubilize available hexachlorophane making it more antiseptic, or more probably to an additional antiseptic effect exerted by accumulated perspiration. In presenting the results we have preferred to record tre⿸te average viable counts from the three treatments rather than to show percentage reductions in the counts of the hexachlorophane preparations over the bar soap. We believe that the latter presentation fres quently gives a false picture of activity. Suffice it to say that the $2.5 \%$ soap gel maintained near sterility over a contact time of one hour whilst the 3 detergent reduced the viable count considerably.

PART IV

Although we believe that the preceding parts of this paper have indicated that the $2.5 \%$ soap gel has satisfactory action against both the transient and resident skin flora and is superior to the $3 \%$ detergem which only acts slowly upon the transients and erratically against the residents we decided te investigate further. Streak plates were taken int mediately after washing with bar soap or the hexachlorophane preparations. This method fraught with difficulties as attempts must be made to 
TABLE IV

RESULTS

\begin{tabular}{|c|c|c|c|c|}
\hline \multirow[t]{2}{*}{ Material Used } & \multicolumn{4}{|c|}{ Average Count per Person } \\
\hline & Name & $\begin{array}{l}24 \\
\text { Hours }\end{array}$ & $\begin{array}{l}48 \\
\text { Hours }\end{array}$ & $\begin{array}{l}\text { Increase over } \\
48 \text { Hours }\end{array}$ \\
\hline Soap (4 tests) & $\begin{array}{l}\text { J.W.L. } \\
\text { J.M.C. } \\
\text { J.A. } \\
\text { J.S. } \\
\text { R.G. } \\
\text { B.D. } \\
\text { Total } \\
\text { Average }\end{array}$ & $\begin{array}{r}79 \cdot 3 \\
244 \cdot 5 \\
102 \cdot 8 \\
15 \cdot 5 \\
225 \cdot 0 \\
117 \cdot 8 \\
784 \cdot 9 \\
130 \cdot 8\end{array}$ & $\begin{array}{r}79 \cdot 3 \\
244 \cdot 5 \\
106 \cdot 0 \\
37 \cdot 6 \\
225 \cdot 0 \\
117 \cdot 8 \\
810 \cdot 2 \\
135\end{array}$ & $\begin{array}{c}0 \\
0 \\
3 \cdot 2 \\
22 \cdot 1 \\
0 \\
0 \\
25 \cdot 3 \\
4 \cdot 2\end{array}$ \\
\hline $2.5 \%$ Hexachlorophane- $23 \%$ potassium soap (6 tests) & $\begin{array}{l}\text { J.W.L. } \\
\text { J.M.C. } \\
\text { J.A. } \\
\text { J.S. } \\
\text { R.G. } \\
\text { B.D. } \\
\text { Total } \\
\text { Average }\end{array}$ & $\begin{array}{r}3 \cdot 9 \\
4 \cdot 5 \\
3 \cdot 0 \\
2 \cdot 2 \\
13 \cdot 8 \\
2 \cdot 6 \\
30 \cdot 0 \\
5\end{array}$ & $\begin{array}{r}4 \cdot 0 \\
5 \cdot 7 \\
3 \cdot 3 \\
5 \cdot 8 \\
19 \cdot 4 \\
3 \cdot 7 \\
41 \cdot 9 \\
7\end{array}$ & $\begin{array}{r}0 \cdot 1 \\
1 \cdot 2 \\
0 \cdot 3 \\
3 \cdot 6 \\
5 \cdot 6 \\
1 \cdot 1 \\
11 \cdot 9 \\
2\end{array}$ \\
\hline Soap ( 5 tests) & $\begin{array}{l}\text { J.W.L. } \\
\text { J.M.C. } \\
\text { J.A. } \\
\text { J.S. } \\
\text { R.G. } \\
\text { Total } \\
\text { Average }\end{array}$ & $\begin{array}{r}776 \cdot 4 \\
209 \cdot 8 \\
139 \cdot 0 \\
13 \cdot 4 \\
99 \cdot 6 \\
1,238 \cdot 2 \\
247 \cdot 6\end{array}$ & $\begin{array}{r}825 \cdot 2 \\
211 \cdot 8 \\
155 \cdot 2 \\
53 \cdot 8 \\
166 \cdot 6 \\
1,412 \cdot 6 \\
282 \cdot 5\end{array}$ & $\begin{array}{r}48 \cdot 8 \\
2 \cdot 0 \\
16 \cdot 2 \\
40 \cdot 4 \\
67 \cdot 0 \\
174 \cdot 4 \\
34 \cdot 9\end{array}$ \\
\hline $3 \%$ Hexachlorophane detergent (6 tests) & $\begin{array}{l}\text { J.W.L. } \\
\text { J.M.C. } \\
\text { J.A. } \\
\text { J.S. } \\
\text { R.G. } \\
\text { Total } \\
\text { Average }\end{array}$ & $\begin{array}{r}31 \cdot 3 \\
86.7 \\
4.4 \\
-7 \\
9 \cdot 6 \\
132.0 \\
26.4\end{array}$ & $\begin{array}{r}58.4 \\
111.4 \\
5 \cdot 8 \\
2.2 \\
14 \cdot 1 \\
191.9 \\
38.4\end{array}$ & $\begin{array}{r}27 \cdot 1 \\
24 \cdot 7 \\
1 \cdot 4 \\
2 \cdot 2 \\
4 \cdot 5 \\
59 \cdot 9 \\
12 \cdot 0\end{array}$ \\
\hline
\end{tabular}

${ }^{1}$ R.G. had a 17-day gap of testing between $2 \cdot 5 \%$ hexachlorophane-23\% potassium soap tests 3 and 4 .

detect $(a)$ the normal levels of both transient and resident bacteria; $(b)$ the period taken to return to normal levels of skin flora after discontinuing medication; and $(c)$ the genuine antibacterial action against both transient and resident organisms as well as mechanical reduction.

The viable counts obtained after washing with unmedicated bar soap represent survivors which have escaped mechanical removal. They may show a preponderance of resident organisms, the transient being removed first, though this may be erratic. Price (1951) and Lowbury et al (1963), amongst others, have stated that a single wash with hexachlorophane is not enough, the reason being invariably attributed to the hypothesis of hexachlorophane forming a film on the skin which, being insoluble, can only act slowly, or not at all if hexachlorophane is only present in insufficient quantity.
If sufficient hexachlorophane can be supplied at one application it might follow that a dramatic reduction in organisms would be immediately obvious depending upon the speed of antiseptic action on the bacteria in direct contact with the preparation. It is important to exclude confusing effects of mechanical reduction and this, we contend, can only be done by employing the method described in Part II.

METHOD The hands were treated with the three preparations as described under the method in part III. The period of washing and rinsing with the $2.5 \%$ soap gel was extended to two minutes (following the initial 30-second application) to bring it into line with the procedures of the other two preparations. The hands were gently dried on a sterile towel and five minutes after the initial contact with the preparation the finger tips were streaked over nutrient agar-1\% Tween 80 plates, which were incubated at $37^{\circ} \mathrm{C}$, and the colonies counted after 24 and 48 hours. 
Increases in viable counts between 24 hours' and 48 hours' incubation varied considerably, from several hundred in the case of bar soap, to about 30 for the $2.5 \%$ soap gel. We therefore decided to analyse the 48-hour counts only. As a general rule counts over 200 have been approximated to the nearest 100 , all counts being carried out by a single technician.

RESULTS The two main blocks of results, the $2.5 \%$ and $3.0 \%$ hexachlorophane preparations, were examined (Table V). The 10 test results on each of the six subjects were analysed: test number 1 for each preparation was discarded (see below), and the remaining nine tests on six subjects were treated collectively, ie, $6 \times 9=54$ tests, but two tests were excluded from the $2.5 \%$ soap gel and one test from the $3 \%$ detergent as sporing organisms were present which confused the result. Although the data are not normally distributed the standard deviation gives a measure of spread for comparison purposes.

\begin{tabular}{lcc} 
& $\begin{array}{c}2.5 \% \text { Hexachlorophane- } \\
\text { 23\% Potassium Soap }\end{array}$ & $\begin{array}{l}\text { 3\%Hexachlorophane } \\
\text { Detergent }\end{array}$ \\
\hline No. in sample & 52 & 53 \\
Average & $6 \cdot 6$ & $33 \cdot 1$ \\
Standard deviation & $7 \cdot 4$ & $46 \cdot 9$ \\
Range & 39 & 212
\end{tabular}

A frequency distribution diagram is shown in Figure 1.

It is apparent that neither preparation has a strictly normal statistical distribution. The $2.5 \%$ soap gel is skewed in the direction of sterility whilst the $3 \%$ detergent has a wider and flatter distribution. As the results of these two preparations are not normally distributed, statistical analyses beyond averages and standard deviations have not been attempted.

The statistical appraisal of the results may be summarized as follows: on average the level of bacterial survivors after washing with the $2.5 \%$ soap gel is about one fifth of the average for the $3 \frac{2}{8}$ detergent; the spread of results around the average is narrower for the $2.5 \%$ soap gel.

Without reference to any other results so fat appraised in this paper, the statistical inference $E$ that, not only is $2.5 \%$ soap gel more effective tha the $3 \%$ detergent but its action is more regular and precise. In more general terms, the results indicate that the $2.5 \%$ soap gel gave low counts which were in fact, near to sterility. The first wash figures were always higher than subsequent counts. This we attribute to deepseated flora being brought to the surface throughout the washing process and at time when the hexachlorophane has been diluted to a level where rapid antibacterial action cannot be expected. (It could be that a repeat wash would eliminate these emerging bacteria as do subsequent washes at a later time, but we have not followed this up.) For this reason we discarded the results of first washes from the analyses. We could not confirm chemically whether an inhibitory concentration of hexachlorophane was left in the skin pores, \& whether re-establishment of deepseated flora takes longer than the six hours between the two washes $i e$, morning and afternoon viable counts. A fair supposition is that after the first wash using the $2.5 \%$ soap gel only surface bacteria are encountere and erratic reductions due to mechanical remov震 do not count. The reduction found can be attro buted to rapid antibacterial action as would be expected on consideration of the results in part II. $\overrightarrow{\vec{O}}$

Whether or not the staphylococcus becomes re established as a resident organism has posed problem, hence washes with the $2.5 \%$ soap gel afte two days without treatment were begun again. Wit the exception of J.A., who had a lacerated finge? the counts were still remarkably low. Fahlberg Swan, and Seastone (1948) stated that the effects of hexachlorophane may persist for several days after

TABLE V

AVERAGE VIABLE COUNTS FIVE MINUTES FROM START OF WASH TREATMENTS ON LEFT AND RIGHT HANDS AFTER 48 HOURS' INCUBATION OF PLATES

\begin{tabular}{l} 
Formulation \\
\hline Bar soap (A) \\
$2 \cdot 5 \%$ Hexachlorophane-23\% potassium soap \\
$2 \cdot 5 \%$ Hexachlorophane-23\% potassium soap \\
(after two days' rest) \\
Bar soap (B) \\
Bar soap (C) \\
(after one week's rest) \\
$3 \%$ Hexachlorophane detergent \\
$3 \%$ Hexachlorophane detergent \\
(after two days' rest) \\
Bar soap (D)
\end{tabular}

\begin{tabular}{|c|c|c|c|c|c|c|}
\hline \multirow{2}{*}{$\begin{array}{l}\text { No. of } \\
\text { Tests }\end{array}$} & \multicolumn{6}{|l|}{ Subject } \\
\hline & J.W.L. & J.M.C. & J.A. & J.S. & R.G. & B.D. \\
\hline $\begin{array}{r}4 \\
10 \\
2\end{array}$ & $\begin{array}{c}700 \\
18 \\
8 \cdot 5\end{array}$ & $\begin{array}{r}207 \\
20 \\
15\end{array}$ & $\begin{array}{r}650 \\
20 \\
104\end{array}$ & $\begin{array}{c}114 \\
5 \cdot 9 \\
9\end{array}$ & $\begin{array}{r}402 \cdot 3 \\
12 \cdot 1 \\
7 \cdot 5\end{array}$ & $\begin{array}{r}216 \cdot 5 \\
29 \cdot 1 \\
6 \cdot 5\end{array}$ \\
\hline $\begin{array}{r}6 \\
10\end{array}$ & $\begin{array}{l}355 \\
511 \cdot 7\end{array}$ & $\begin{array}{l}167 \cdot 8 \\
268 \cdot 3\end{array}$ & $\begin{array}{l}53 \cdot 8 \\
51 \cdot 4\end{array}$ & $\begin{array}{l}51 \cdot 5 \\
43 \cdot 9\end{array}$ & $\begin{array}{l}132 \\
110 \cdot 4\end{array}$ & $\begin{array}{r}57 \cdot 5 \\
203 \cdot 3\end{array}$ \\
\hline $\begin{array}{r}10 \\
2\end{array}$ & $\begin{array}{l}57 \cdot 3 \\
21 \cdot 5\end{array}$ & $\begin{array}{c}25 \cdot 4 \\
282\end{array}$ & $\begin{array}{l}48 \cdot 1 \\
12 \cdot 5\end{array}$ & $\begin{array}{c}39 \cdot 8 \\
3\end{array}$ & $\begin{array}{l}58 \cdot 6 \\
42\end{array}$ & $\begin{array}{l}31 \cdot 2 \\
42\end{array}$ \\
\hline 8 & 520 & $249 \cdot 6$ & $41 \cdot 3$ & 17 & $134 \cdot 8$ & 189.1 \\
\hline
\end{tabular}




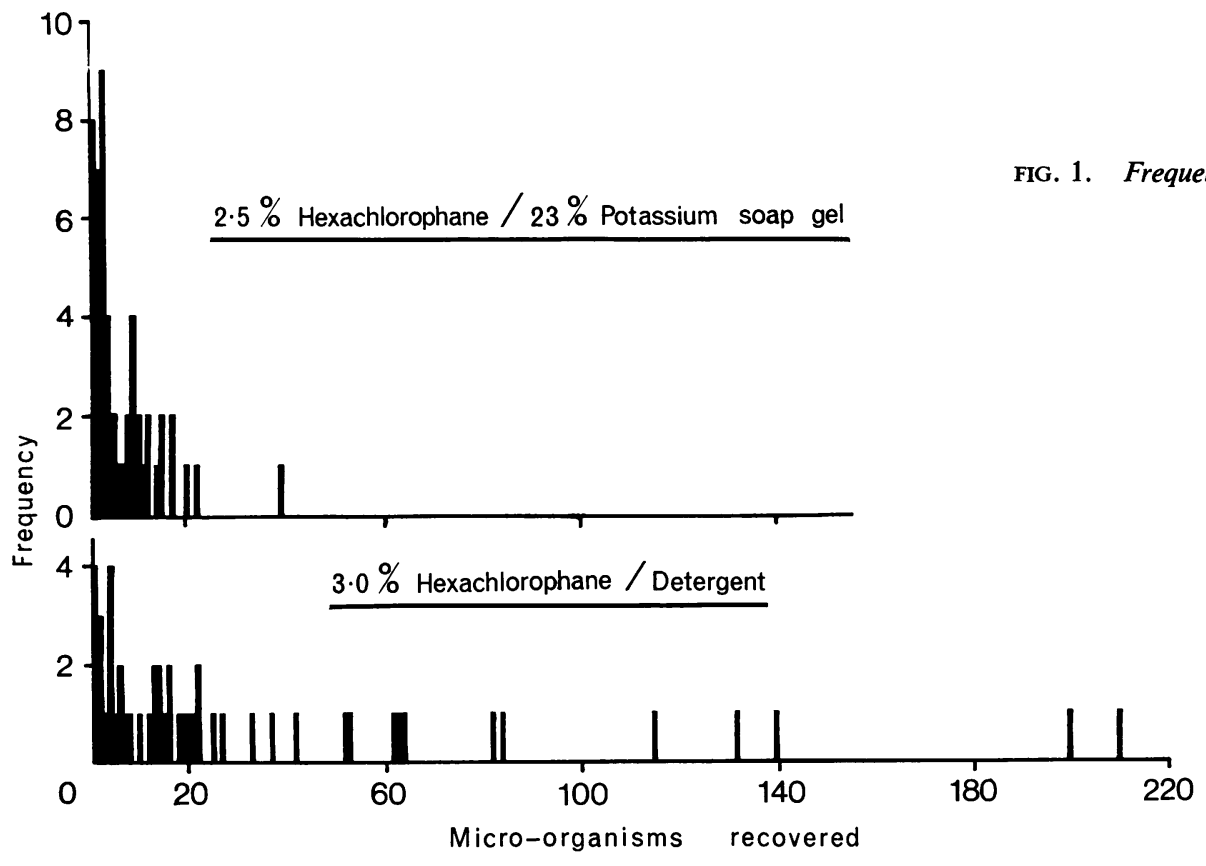

cessation of use, and this seems evident in the case of J.S., J.A., and D.B. but not in J.W.L. or J.M.C.

The persistent inhibition of resident staphylococci has two indivisible effects: (1) the speed of reestablishment of the staphylococci and (2) the antibacterial effect of residual hexachlorophane in the pores. Since we obtained the impression that certain subjects were not re-establishing resident flora rapidly, we allowed a resting period of one week between soap washes $B$ and $C$ in order (see Table V) that relatively normal levels of both resident and transient bacteria could re-establish.

The results obtained with the $3 \%$ detergent were again erratic as shown by statistical appraisal. The first count was high (compared with the $2.5 \%$ soap gel) and has been excluded from the analysis, but subsequent counts are erratic and unpredictable which implies variable antibacterial and mechanical action. After the one week rest the results were equally erratic.

We included bar soap essentially as a qualitative control, but statistical appraisal of the results would serve no useful purpose, and it is sufficient to say that the distribution is similar to that of the $3 \%$ detergent, but flatter and wider, indicative of mechanical removal only.

We consider that great care must be shown when testing numerous skin preparations within a short time due to unpredictable residual effects and erratic re-establishment of resident organisms. As an example, the $2.5 \%$ soap gel was used to wash the hands and counts were made. The following day a non-medicated liquid soap was employed, the counts being very low as compared with those from the hexachlorophane wash. The reason for this is most probably due to the unmedicated soap merely having to remove transient organisms mechanically, deepseated residents having been previously eliminated by the hexachlorophane. The dangers of misinterpretation from such results are all too obvious.

\section{DISCUSSION}

The vehicle in which hexachlorophane is suspended appears to be of the utmost importance. It is difficult to decide whether the detergent formulation depresses potential activity of hexachlorophane, but that soap activates the antibacterial action would seem irrefutable on the evidence presented. It is unfortunate that the main types of hexachlorophane formulation previously investigated, $i e$, bar soap and types of detergent are what we consider abnormal by virtue of their chemistry, methods of application and, in the $3 \%$ detergent preparation, ability to repel water.

To obtain the maximum concentration of hexachlorophane for surface disinfection of transient organisms we have applied the $2.5 \%$ soap gel neat; in effect we have used it as a cream. It is also our 
belief that this maximum of hexachlorophane should be available in a suitable antibacterial form. It appears that the $3 \%$ detergent demands some intrinsic property of the skin for optimum action, a property not present in all subjects. The soap gel hexachlorophane does not appear to depend on such phenomena.

Although it seems difficult to distinguish between a residual effect of hexachlorophane film and lack of re-establishment of deepseated organisms it appears that the soap preparation possesses all the properties of the detergent preparation but without its erratic nature. This may be because the soap removed grease from the pores more efficiently, facilitating a better film coating, and/or the hexachlorophane is deposited more finely and is more easily solubilized by the skin secretions. Again, since the $2.5 \%$ soap gel is a rapid antiseptic due to its solubilized state, it may be that the hexachlorophane is deposited on the skin in a solubilized form.

The previous statements that hexachlorophane is effective only against Gram-positive cocci is fallacious, since it really means that hexachlorophane preparations so far investigated have shown a Grampositive specificity. We contend that hexachlorophane is a chlorphenolic substance and as such would obey the rules of phenolic formulations and is not a law unto itself. For example, coal tar fractions, whilst having some intrinsic antibacterial activity, are essentially activated by the medium in which they are suspended: cresols, xylenols, and their halogenated derivatives obey the same rules. An excellent summary of these phenomena is given by Sykes (1965).

The statistical appraisal of the results obtained in part IV reveals a constant low number of surviving bacteria on using the $2.5 \%$ soap gel, indicative of antibacterial action (superior to that of the $3 \%$ detergent) against both transient and deepseated organisms. We have further shown that the $2.5 \%$ soap gel can rapidly kill Gram-negative organisms on the skin as well as the Gram-positive flora when applied as we suggest.

Throughout this work the $2.5 \%$ hexachlorophane$23 \%$ potassium soap gel has referred to a commercial formulation produced by the action of the alkali upon a suitable blend of fatty acids and hexachlorophane. It is impossible to say that the antibacterial action evidenced in this paper could be obtained simply by adding hexachlorophane to potassiu蒫 soap or by using other grades of fatty acids.

A certain amount of skin irritation and chappin after the application of the $2.5 \%$ soap gel has beet reported, and since the original work in this paper a $2.5 \%$ hexachlorophane- $23 \%$ potassium soap ge containing emollients has become available which we have examined by many of the methods described above and found to be at least as rich in germicids properties as those of the non-emollient preparatio $\vec{Q}$

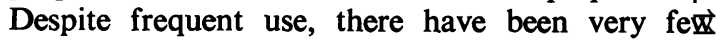
complaints regarding skin irritation. One mu\& realize, however, that whatever skin preparation $\overrightarrow{\hat{s}}$ used there is bound to be someone who is "sensitive It is known that some people are sensitive to hexa chlorophane, so that any preparation containing $\overrightarrow{\text { if }}$ would cause irritation. It is important that a田 excessive amount is not used at each application The products have been tested repeatedly on laboratory and hospital staff with no sign of local irritation

The author wishes to thank Dr E. H. Gillespie, of the Public Health Laboratory, Sheffield, for his invaluable advice and criticism and Mr E. J. Miles and Mr J. AO Bright for advice on surface activity; Mrs Janet M. Childo for much of the original experimentation; Mrs J. Alleng Mrs M. Loxley and Mrs J. Ridge for technical assistance Mr H. G. Ogden and Mr D. Mann for statistical advice and appraisal; and Mrs M. Woods for secretari assistance.

\section{REFERENCES}

Bean, H. S., and Berry, H. (1953). J. Pharm. Pharmacol., 5, 632. Fahlberg, W. J., Swan, J. C., and Seastone, C. Y. (1948). J. Bac? 56, 323.

Higgins, M. (1950). Mth. Bull. Minist. Hlth Lab. Serv., 9, 50.

Hufnagel, C. A., Walter, C. W., and Howard, R. W. (1948). Surger 23, 753.

Lowbury, E. J. L., Lilly, H. A., and Bull, J. P. (1963). Brit. med. ig 1,1251 .

$\overline{\text { Price }}, \overline{\mathrm{T}}, \overline{\mathrm{l}}$ (1964). Ibid., 2, 230.

Price, P. B. (1951). Ann. Surg., 134, 476. 1957). In Antiseptics, Disinfectants, Fungicides, and Chemicz and Physical Sterilisation, 2nd ed., edited by G. F. Reddis p. 415 . Kimpton, London.

Seastone, C. V. (1947). Surg. Gynec. Obstet., 84, 355.

Smylie, H. G., Webster, C. U., and Bruce, M. L. (1959). Brit. med. $\frac{D}{6}$ 2, 606.

Sykes, G. (1965). Disinfection and Sterilisation, 2nd ed. ch. $1 \frac{20}{\text { pp. } 311-321 \text {. }}$

Traub, E. F., Newhall, C. A., and Fuller, J. R. (1944). Surg. Gyne אo Obstet., 79, 205.

Udinski, H. J. (1945). J. med. Soc. N.J., 42, 15.

${ }^{1}$ The $2.5 \%$ hexachlorophane-23\% potassium soap gel used in th work is marketed as Zalpon antibacterial washing cream and the emollient formulation as Steridermis. 